\title{
Chromosomal distribution of microsatellite repeats in Amazon cichlids genome (Pisces, Cichlidae)
}

\author{
Carlos Henrique Schneider', Maria Claudia Gross' ${ }^{1}$, Maria Leandra Terencio², \\ Édika Sabrina Girão Mitozo de Tavares', Cesar Martins ${ }^{3}$, Eliana Feldberg ${ }^{4}$
}

\begin{abstract}
I Universidade Federal do Amazonas, Instituto de Ciências Biológicas, Departamento de Genética, Laboratório de Citogenômica Animal, Av. General Rodrigo Otávio, 3000, Japiim, Zip code 69077-000 Manaus, AM, Brazil 2 Universidade Federal da Integração Latino Americana, Laboratório de Genética, Av. Tarquínio Joslin dos Santos, 1000, Jardim Universitário, Zip code 85857-190, Foz do Iguaçu, PR, Brazil 3 Universidade Estadual Paulista Júlio de Mesquita Filho - UNESP, Instituto de Biociências, Departamento de Morfologia, Laboratório Genômica Integrativa, Rubiāo Junior, Zip code 18618-000 Botucatu, SP, Brazil 4 Instituto Nacional de Pesquisas da Amazônia, Laboratório de Genética Animal, Av. André Araújo, 2936 Zip Code 69077-000, Manaus, AM, Brazil
\end{abstract}

Corresponding author: Carlos Henrique Schneider (schneider.carloshenrique@gmail.com)

Academic editor: E. Gornung | Received 3 July 2015 | Accepted 21 August 2014 | Published 14 September 2015 http://zoobank.org/663D53CE-DFC1-47D1-B0D7-782AB3168A03

Citation: Schneider CH, Gross MC, Leandra Terencio M, de Tavares ÉSGM, Martins C, Feldberg E (2015) Chromosomal distribution of microsatellite repeats in Amazon cichlids genome (Pisces, Cichlidae). Comparative Cytogenetics 9(4): 595-605. doi: 10.3897/CompCytogen.v9i4.5582

\begin{abstract}
Fish of the family Cichlidae are recognized as an excellent model for evolutionary studies because of their morphological and behavioral adaptations to a wide diversity of explored ecological niches. In addition, the family has a dynamic genome with variable structure, composition and karyotype organization. Microsatellites represent the most dynamic genomic component and a better understanding of their organization may help clarify the role of repetitive DNA elements in the mechanisms of chromosomal evolution. Thus, in this study, microsatellite sequences were mapped in the chromosomes of Cichla monoculus Agassiz, 1831, Pterophyllum scalare Schultze, 1823, and Symphysodon discus Heckel, 1840. Four microsatellites demonstrated positive results in the genome of $C$. monoculus and $S$. discus, and five demonstrated positive results in the genome of $P$. scalare. In most cases, the microsatellite was dispersed in the chromosome with conspicuous markings in the centromeric or telomeric regions, which suggests that sequences contribute to chromosome structure and may have played a role in the evolution of this fish family. The comparative genome mapping data presented here provide novel information on the structure and organization of the repetitive DNA region of the cichlid genome and contribute to a better understanding of this fish family's genome.
\end{abstract}

Copyright Carlos Henrique Schneider et al. This is an open access article distributed under the terms of the Creative Commons Attribution License (CC BY 4.0), which permits unrestricted use, distribution, and reproduction in any medium, provided the original author and source are credited. 


\section{Keywords}

Karyotype evolution, fluorescence in situ hybridization, repetitive DNA, genome organization

\section{Introduction}

The fish family Cichlidae exhibits high species richness with approximately 3,000 species distributed in Central and South America, Africa, and South India (Kullander 1998, Kocher 2004). The evolution of this family is characterized by repeated adaptive radiation and sympatric speciation (Schliewen et al. 1994, Seehausen 2006). Moreover, these fish are considered to be an excellent model for evolutionary studies because of their morphological and behavioral adaptations to a wide diversity of explored ecological niches (Lowe-McConnell 1991). Approximately 400 species have been identified in a wide range of habitats in the Neotropical region. The Amazon exhibits the highest diversity of Cichlidae, with more than 300 identified species (Kullander 2003).

In Neotropical cichlids, the diversity of morphological adaptations does not result from variations in the diploid number because most species have 48 chromosomes (Feldberg et al. 2003). However, the species of this family exhibit a dynamic genome with variations in structure and karyotype composition and organization, as demonstrated by the DNA sequencing and the physical chromosome mapping of several repetitive DNA sequences, such as telomere sequences; retrotransposons isolated from Xiphophorus maculatus Günther, 1866 (Rex1, Rex3, Rex6); retrotransposon isolated from Astronotus ocellatus Agassiz, 1831 similar to Rex3 (AoRex3); long interspersed elements isolated from Astronotus ocellatus (AoLINE); retrotransposon isolated from Cichla kelberi Kullander \& Ferreira, 2006 (RCk); transposon isolated from Caenorhabditis elegans Maupas, $1900(T c 1)$; the $18 \mathrm{~S}$ and $5 \mathrm{~S}$ ribosomal gene sequences; and U1 spliceosomal small nuclear RNA (U1 snRNAs) (Vicari et al. 2006, Gross et al. 2009, Mazzuchelli and Martins 2009, Teixeira et al. 2009, Gross et al. 2010, Poletto et al. 2010, Cabral-de-Mello et al. 2012, Valente et al. 2011, Schneider et al. 2013a, Schneider et al. 2013b). Moreover, in this fish family, repetitive DNAs, such as transposable elements, co-localize or are associated with ribosomal DNAs, which suggests their roles in the duplication and dispersion of repetitive rDNA sequences (Gross et al. 2010, Schneider et al. 2013a, Schneider et al. 2013b, Nakajima et al. 2012).

Repetitive DNA sequences display a high degree of polymorphism because of the variation in the number of repetitive units, which results from a specific evolutionary dynamics. Among these elements, microsatellites (or short tandem repeats) are the most polymorphic and are formed of short sequences of one to six nucleotides repeated in tandem throughout the DNA (Tautz and Renz 1984). Because of their supposed neutral evolution, these molecular markers have been widely used in population genetics, to identify taxonomic limits, and in hybridization and forensic studies (Goldstein and Pollock 1997, Filcek et al. 2005, Racey et al. 2007, McCusker et al. 2008). However, recent research has demonstrated that certain microsatellites are 
functional and may affect gene regulation (Kashi and King 2006, Gemayel et al. 2010, Sonay et al. 2015); evolution of orphan genes (Palmieri et al. 2014, Schlötterer 2015); involved in chromosomal rearrangements (Kamali et al. 2011) and be involved with increased or diminishes likelihood of disease related alleles size (Ananda et al. 2014; Padeken et al. 2015).

The chromosomal mapping of microsatellite sequences has been little examined. This approach is primarily used to study the evolution of different sex-determining chromosome systems (Li et al. 2010, Pokorná et al. 2011, Terencio et al. 2013). Considering that microsatellites are the most dynamic genomic component, a better understanding of their chromosomal organization is important for improving knowledge regarding the role of repetitive DNA elements in the mechanisms of chromosomal evolution and heterochromatin composition.

Cichla monoculus Agassiz, 1831 has a karyotype with $2 \mathrm{n}=48$ subtelo/acrocentric (st/a) chromosomes, described as basal for cichlids, and little heterochromatin. Although Pterophyllum scalare Schultze, 1823 also has $2 n=48$ chromosomes, this species differs in karyotype formula with meta/submetacentric $(\mathrm{m} / \mathrm{sm})$ chromosomes due to chromosomal inversions and accumulation of heterochromatin in the pericentromeric regions. The highest diploid number described for this group is found in species of the genus Symphysodon Heckel, 1840, which has $2 \mathrm{n}=60$ chromosomes, as well as large heterochromatic blocks (Schneider et al. 2013a). Thus, this study provides a physical mapping of microsatellite sequences on the chromosomes of three Neotropical cichlid fish species (C. monoculus, $P$. scalare, and $S$. discus), that occupy different phylogenetic positions, and contributes to a better understanding of the chromosomal organization and evolution of this fish family.

\section{Methods}

Specimens of C. monoculus (four males and four females), P. scalare (three males and three females) were collected in Catalão Lake, confluence of the Negro/Solimóes Rivers (3 $\left.09^{\prime} 47.44^{\prime \prime} \mathrm{S} / 59^{\circ} 54^{\prime} 51.39^{\prime \prime W}\right)$ and $S$. discus (two males and two females) in Negro River $\left(0^{\circ} 56^{\prime} 06.43^{\prime \prime S} / 62^{\circ} 56^{\prime} 22.61^{\prime \prime W}\right)$. The specimens were caught in the wild with sampling permission (ICMBio SISBIO 10609-1/2007). All of the individuals were euthanatized with Eugenol (clove oil).

Mitotic chromosomes were obtained from kidney cells using an air-drying protocol (Bertollo et al. 1978).

Eight microsatellites (Amado et al. 2008; Passos et al. 2010) were mapped using fluorescence in situ hybridization (FISH) during the mitotic metaphase of C. monoculus, $P$. scalare, and $S$. discus (Table 1). The repetitive sequence probes were labeled with digoxigenin-11-dUTP or biotin-16-dUTP (Dig-Nick Translation Mix and BioNick Translation Mix; Roche) using nick translation reactions following the manufacturer's instructions. Anti-digoxigenin rhodamine (Roche) and streptavidin/Alexa Fluor 488 (Life Technologies) were used to detect the signal. FISH was performed on mitotic 
Table I. Repetitive sequences hibridized to cichlid chromosomes. (+) positive hybridization signals detected; (-) absence of hibridization signals.

\begin{tabular}{c|c|c|c}
\hline Repeat motif & C. monoculus & P. scalare & S. discus \\
\hline$(\mathrm{CA})_{16}$ & + & + & + \\
\hline$(\mathrm{AC})_{7}$ & + & - & - \\
\hline$(\mathrm{GT})_{13}$ & + & + & - \\
\hline$(\mathrm{GA})_{12}$ & - & + & + \\
\hline$(\mathrm{GAATA})_{8}$ & + & + & - \\
\hline$(\mathrm{GAGAA})_{12}$ & - & + & + \\
\hline$(\mathrm{GT})_{9} \mathrm{CA}(\mathrm{GT})_{7} \mathrm{CG}(\mathrm{GT})_{19}$ & - & - & + \\
\hline$(\mathrm{CT})_{14} \mathrm{GT}(\mathrm{CT})_{5}(\mathrm{CG})_{2}(\mathrm{CT})_{9}$ & - & - & - \\
\hline
\end{tabular}

chromosome spreads (Pinkel et al. 1986). The FISH was performed with high stringency $(2.5 \mathrm{ng} / \mu \mathrm{l}$ of DNA, $50 \%$ deionized formamide, $10 \%$ dextran sulfate and $2 \mathrm{xSSC}$ at $37^{\circ} \mathrm{C}$ for $\left.18 \mathrm{~h}\right)$. The chromosomes were counterstained with DAPI $(2 \mu \mathrm{g} / \mathrm{ml})$ in the Vectashield mounting medium (Vector).

\section{Results}

Four microsatellites, among which three were dinucleotides and one was a pentanucleotide, exhibited positive reactions in the genome of C. monoculus (Table 1). Hybridizations with the pentanucleotide microsatellite (GAATA) ${ }_{8}$ displayed dispersed signals in all of the chromosomes. Moreover, conspicuous markings were observed in several chromosome pairs. However, one chromosome pair did not exhibit any homology with the probe (Fig. 1a). The microsatellite (CA) ${ }_{16}$ was distributed in all of the chromosomes of C. monoculus, except for one pair. In most chromosomes, the microsatellite displayed a dispersed distribution, and in several cases, the markings were conspicuous (Fig. 1b). A dispersed pattern was observed after hybridization with the microsatellite $(\mathrm{GT})_{13}$, whereas a strong signal occurred in the telomeric, interstitial or centromeric regions of the chromosomes (Fig. 1c). Conversely, hybridizations with the microsatellite $(\mathrm{AC})_{7}$ resulted in only two positive chromosome pairs, one with markings in the telomeric region of the short arm and in the interstitial region of the long arm and the other with markings in both telomeric regions (Fig. 1d).

Five microsatellites were mapped in the genome of $P$. scalare: three dinucleotides and two pentanucleotides (Table 1). The microsatellites (GAATA), (CA) ${ }_{16}$ and $(\mathrm{GT})_{13}$, which were dispersed in C. monoculus, exhibited clustered signals in $P$. scalare. The microsatellite (CA) ${ }_{16}$ was mapped on centromeric blocks of five chromosome pairs (Fig. 1f), other signals were located in telomeric, centromeric and interstitial regions of most chromosomes (Fig. 1e and 1g). Additionally, the microsatellites (GA) ${ }_{12}$ and (GAGAA) ${ }_{12}$ exhibited similar patterns of conspicuous markings in the centromeres. However, in the case of (GAGAA) ${ }_{12}$, one chromosome pair did not display any markings (Fig. 1h, i). 


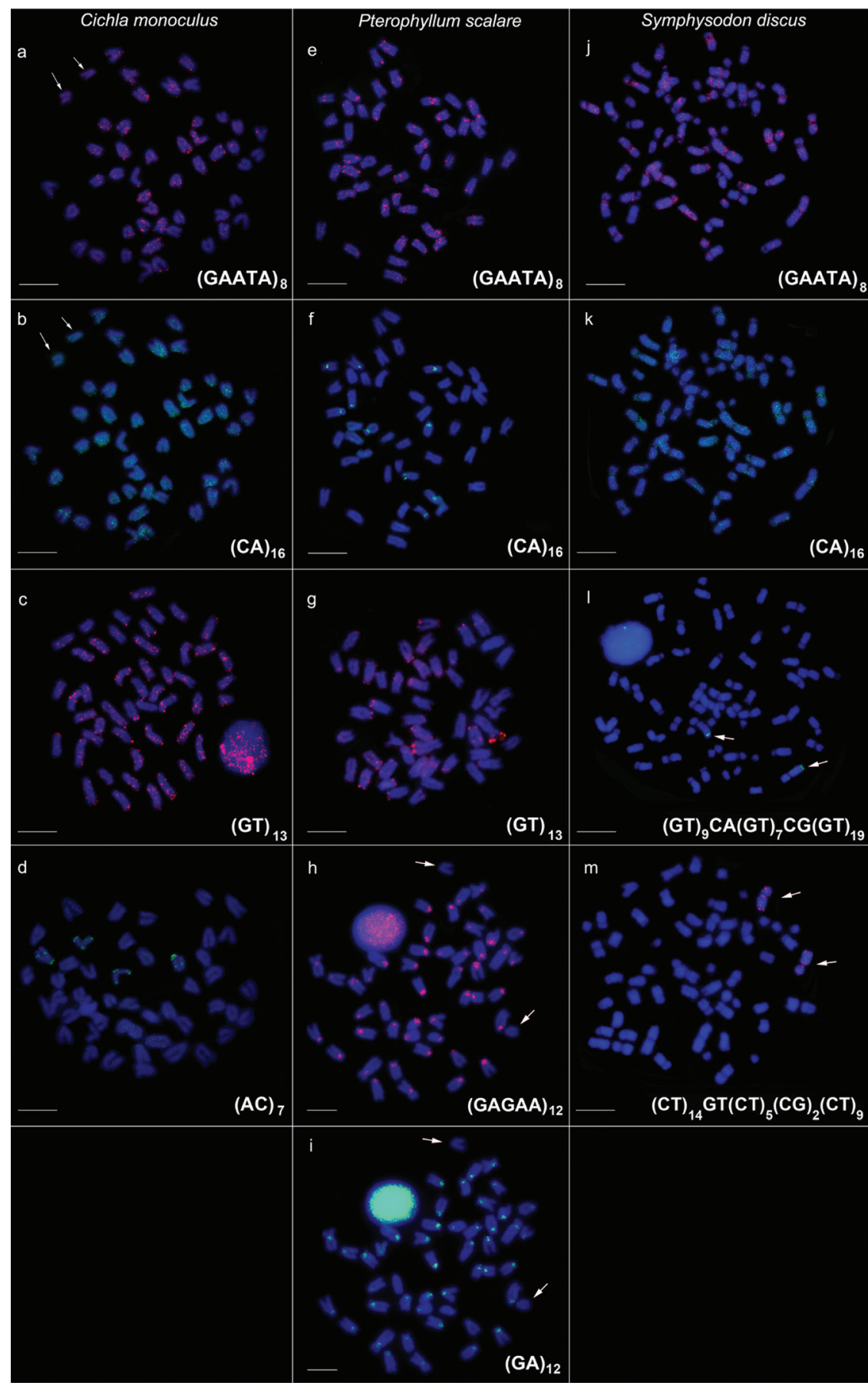

Figure I. Metaphase chromosomes of $C$. monoculus, $P$. scalare and $S$. discus hybridized with microsatellite sequences $(\mathbf{a}-\mathbf{m})$. Arrow shows no signs of hybridizations in $\mathbf{a}, \mathbf{b}, \mathbf{h}, \mathbf{i}$ and chromosomes positive for microsatellite in $\mathbf{I}, \mathbf{m}$. The probes detection was performed with streptavidin Alexa Fluor 488 (green) or anti-digoxigenin rhodamine (red). Chromosomes were counterstained with DAPI. Scale bar: $10 \mu \mathrm{m}$. 
Four microsatellites were mapped in $S$. discus. In this species, the microsatellites (GAATA) ${ }_{8}$ and (CA) ${ }_{16}$ exhibited patterns similar to that of $C$. monoculus with dispersed signals and conspicuous markings in the centromeric region (Fig. 1j, 1k). Only one chromosome pair displayed positive results for microsatellites $(\mathrm{GT})_{9} \mathrm{CA}(\mathrm{GT})_{7} \mathrm{CG}(\mathrm{GT})_{19}$ and $(\mathrm{CT})_{14} \mathrm{GT}(\mathrm{CT})_{5}(\mathrm{CG})_{2}(\mathrm{CT})_{9}$. The first was located in the telomeric region of the long arm, and the latter was located in the centromeric and telomeric regions (Fig. 11, m).

\section{Discussion}

The repetitive regions of the genome typically do not undergo the selective pressure that affects non-repetitive sequences, and most microsatellite sequences evolve neutrally and supposedly do not affect an individual phenotype (Schlötterer 2000). However, recent studies have identified functional microsatellites that affect the physical aspect of an individual (Kashi and King 2006, Gemayel et al. 2010, Padeken et al. 2015). These putative functional microsatellites are primarily located in or near gene regions, and there is variation in the number of times that the motif is repeated, which is related to the ability of the microsatellites to modify gene expression or change protein sequences (Wren et al. 2000, Li et al. 2004, Vinces et al. 2009, Gemayel et al. 2010). In addition to this functional aspect, repetitive DNA variants that include microsatellites may serve as efficient agents for adaptive evolution (King and Kashi 2009).

In all classes of repetitive DNA, there appears to be a general trend of increased matrix length throughout evolutionary time. Moreover, highly repetitive sequences tend to accumulate in regions of low recombination, such as centromeres and telomeres, whereas repetitive regions in euchromatin are much more susceptible to crossingover (Pathak and Ali 2012).

Overall, the chromosome hybridization of microsatellites demonstrated contrasting patterns of abundance and localization of these sequences in the chromosomes of C. monoculus, $P$. scalare and $S$. discus, which indicates that the repetitive sequences have accumulated differently among the genomes. Although the three species exhibited a wide distribution of microsatellites (GAATA) ${ }_{8}$ and (CA) ${ }_{16}$ in their genome, clustering of these markers was observed in $P$. scalare, which represents a derived species in the phylogeny of Cichlinae (Smith et al. 2008). Clustering of repetitive sequences in derived species was also observed for transposable elements of this fish family (Gross et al. 2009; Valente et al. 2011; Schneider et al. 2013b). The association between microsatellites and the abundance of retrotransposable elements has been suggested as a mechanism that may increase the number of microsatellites (Nadir et al. 1996). However, in several organisms, a relationship between the high density of transposable elements and a high rate of microsatellites is not observed (Schlötterer 2000, 2015).

Position of the microsatellite sequences mapped in this study was similar to that observed for retroelements in the same species, with signals scattered throughout chromosomes and others clustered in terminal and centromeric regions (Schneider et al. 2013b). This outcome suggests that these sequences may be involved in the structural 
formation of the centromere and the telomere. Moreover, the microsatellites present in the centromeric and subtelomeric regions differ among cichlid species, which reinforces the importance of these sequences in the evolution of the different groups.

The centromere is an essential structure with several functional roles in the segregation of replicated chromosomes to daughter cells. These roles include genetic/epigenetic marking and the assembly of the protein complex of the kinetochore during the cell cycle, providing checkpoints to control mitosis, the release of sister-chromatid cohesion, chromosome migration to the cellular poles and cytokinesis (Santaguida and Musacchio 2009, Allshire and Karpen 2008, Perpelescu and Fukagawa 2011). Centromeres comprise long stretches of tandem repeats of satellite and microsatellite DNA, which are essential for binding with protein complexes (Verdaasdonk and Bloom 2011, Kalitsis and Choo 2012). Centromeric DNA sequences typically present high evolutionary rates and variation among species or chromosomes of the same species is common (Plohl et al. 2008). Thus, the centromeric region of $P$. scalare is rich in (GAGAA ${ }_{12}$ microsatellite sequences, but one chromosome pair does not display any hybridization signals. As well, in $C$. monoculus and $S$. discus, the centromere region is not rich in (GA) ${ }_{12}$ and (GAGAA) ${ }_{12}$.

Another chromosome region with a high evolutionary rate is the subterminal region. Typically, this region is composed of different classes of repetitive DNA that may help stabilize the terminal portion of the chromosomes because of the possibility of amplifying these sequences even in the absence of telomerase (Jain et al. 2010, Torres et al. 2011). In $S$. discus, the microsatellites (GT) ${ }_{9} \mathrm{CA}(\mathrm{GT})_{7} \mathrm{CG}(\mathrm{GT})_{19}$ and $(\mathrm{CT})_{14} \mathrm{GT}(\mathrm{CT})_{5}(\mathrm{CG})_{2}(\mathrm{CT})_{9}$ are present in the subterminal region of two chromosome pairs, whereas these markers were not observed in the chromosomes of $C$. monoculus and $P$. scalare. The same result was obtained for the microsatellite $(\mathrm{AC})_{7}$, which was observed only in C. monoculus. The microsatellites (GAATA) ${ }_{8}$ and (GT) ${ }_{13}$ were observed in the subterminal regions of $C$. monoculus and $P$. scalare but not in $S$. discus. In $P$. scalare, a conspicuous marking of the microsatellite $(\mathrm{GT})_{13}$ was observed in the terminal region of the largest chromosome pair, where the $18 \mathrm{~S}$ ribosomal gene is located (Schneider et al. 2013a), indicating synteny between these two classes of repetitive DNA.

Still, heterochromatin of the cichlids analyzed here was located in the centromeric or pericentromeric regions in most of the chromosomes (Schneider et al. 2013). These regions show positive signals of hybridization for different microsatellites analyzed, as well as other repetitive elements (Schneider et al. 2013). The most common cellular mechanism that prevents activation and expansion of repetitive elements is the formation of heterochromatin over their sequences and three epigenetics pathways interconnected ensure the silencing of their elements: methylation of $\mathrm{H} 3 \mathrm{~K} 9$, DNA methylation and the germ-line specific PIWI pathway (Padeken et al. 2015).

The regulation of the repetitive sequences is not yet clear and depends largely on new technologies to clarify their function (Padeken et al. 2015), but the comparative mapping data presented provide novel information on the structure and organization of the repetitive region of the genome of cichlids and suggest that microsatellites contribute to chromosome structure and may have played a role in the evolution of this fish family. 


\section{Acknowledgments}

This study was supported by the Conselho Nacional de Pesquisa and Desenvolvimento Tecnológico (CNPq—140816/2009-7 CHS scholarship), Instituto Nacional de Pesquisas da Amazônia/Biologia de Água Doce e Pesca Interior (INPA/BADPI), Fundação de Amparo de Pesquisas do Amazonas (PRONEX FAPEAM/CNPq 003/2009), Fundação de Amparo a Pesquisa do Estado de São Paulo (FAPESP) and the CNPq/ Universal (476292/2013-1).

\section{References}

Allshire RC, Karpen GH (2008) Epigenetic regulation of centromeric chromatin: old dogs, new tricks? Nature Reviews Genetics 9: 923-937. doi: 10.1038/nrg2466

Amado MV, Hrbek T, Gravena W, Fantin C, Assunção EM, Astolfi-Filho S, Farias IP (2008) Isolation and characterization of microsatellite markers for the ornamental discus fish Symphysodon discus and cross-species amplification in other Heroini cichlid species. Molecular Ecology Resources 8: 1451-1453. doi: 10.1111/j.1755-0998.2008.02200.x

Ananda G, Hile SE, Breski A, Wang Y, Kelkar Y, Makova KD, Eckert KA (2014) Microsatellite interruptions stabilize primate genomes and exist as population-specific single nucleotide polymorphisms within individual human genomes. PLoS Genetics 10: e1004498. doi: 10.1371/journal.pgen. 1004498

Bertollo LAC, Takahashi CS, Moreira-Filho O (1978) Cytotaxonomic considerations on Hoplias lacerdae (Pisces, Erythrinidae). Brazilian Journal of Genetics 1: 103-120.

Cabral-de-Mello DC, Valente GT, Nakajima RT, Martins C (2012) Genomic organization and comparative chromosome mapping of the U1 snRNA gene in cichlid fish, with an emphasis in Oreochromis niloticus. Chromosome Research 20: 279-292. doi: 10.1007/ s10577-011-9271-y

Feldberg E, Porto JIR, Bertollo LAC (2003) Chromosomal changes and adaptation of cichlid fishes during evolution. In: Val AL, Kapoor BG (Eds) Fish adaptation. Science Publishers, Enfield, USA, 285-308.

Filcek KB, Gilmore SA, Scribner KT, Jones ML (2005) Discriminating lamprey species using multilocus microsatellite genotypes. North American Journal of Fisheries Management 25: 502-509. doi: 10.1577/M03-206.1

Gemayel R, Vinces MD, Legendre M, Verstrepen KJ (2010) Variable tandem repeats accelerate evolution of coding and regulatory sequences. Annual Reviews of Genetics 44: 445-477. doi: 10.1146/annurev-genet-072610-155046

Goldstein DB, Pollock DD (1997) Lauching microsatellities. Jounal of Heredity 88: 335-342. doi: 10.1093/oxfordjournals.jhered.a023114

Gross MC, Schneider CH, Valente GT, Porto JIR, Martins C, Feldberg E (2009) Comparative cytogenetic analysis of the genus Symphysodon (Discus Fishes, Cichlidae): chromosomal characteristics of retrotransposons and minor ribosomal DNA. Cytogenetic and Genome Research 127: 43-53. doi: 10.1159/000279443 
Gross MC, Schneider CH, Valente GT, Porto JIR, Martins C, Feldberg E (2010) Variability of $18 \mathrm{~S}$ rDNA locus among Symphysodon fishes: chromosomal rearrangements. Journal of Fish Biology 76: 1117-1127. doi: 10.1111/j.1095-8649.2010.02550.x

Jain D, Hebden AK, Nakamura TM, Miller KM, Cooper JP (2010) HAATI survivors replace canonical telomeres with blocks of generic heterochromatin. Nature 467: 223-227. doi: 10.1038 /nature09374

Kalitsis P, Choo KHA (2012) The evolutionary life cycle of the resilient centromere. Chromosoma 121: 327-340. doi: 10.1007/s00412-012-0369-6

Kamali M, Sharakhova MV, Baricheva E, Karagodin E, Tu Z, Sharakhov IV (2011) An integrated chromosome map of microsatellite markers and inversion breakpoints for an Asian malaria mosquito, Anopheles stephensi. Journal of Heredity 102: 719-726. doi: 10.1093/ jhered/esr072

Kashi Y, King DG (2006) Simple sequence repeats as advantageous mutators in evolution. Trends in Genetics 22: 253-259. doi: 10.1016/j.tig.2006.03.005

King D, Kashi GY (2009) Heretical DNA sequences? Science 326: 229-230. doi: 10.1126/ science.326_229

Kocher TD (2004) Adaptive evolution and explosive speciation: the cichlid fish model. Nature Reviews Genetics 5: 288-298. doi: 10.1038/nrg1316

Kullander SO (1998) A phylogeny and classification of the South America Cichlidae (Teleostei: Perciformes). In: Malabarba LR, Reis RE, Vari RP, Lucena ZMS, Lucena CAS (Eds) Phylogeny and classification of neotropical fishes. EdiPuc, Porto Alegre, 461-498.

Kullander SO (2003) Family Cichlidae. In: Reis RE, Kullander SO, Ferraris JrCJ (Eds) Check List of the Fresh-water Fishes of South and Central America. EdiPuc, Porto Alegre, 605-654.

Li YC, Korol AB, Fahima T, Nevo E (2004) Microsatellites within genes: structure, function, and evolution. Molecular Biology and Evolution 21: 991-1007. doi: 10.1093/molbev/msh073

Li J, Phillips RB, Harwood AS, Koop BF, Davidson WS (2010) Identification of the sex chromosomes of brown trout (Salmo trutta) and their comparison with the corresponding chromosomes in Atlantic salmon (Salmo salar) and rainbow trout (Oncorhynchus mykiss). Cytogenetic and Genome Research 133: 25-33. doi: 10.1159/000323410

Lowe-McConnell RH (1991) Ecology of cichlids in South American and African waters, excluding the African Great Lakes. In: Keenleyside MHA (Ed.) Cichlid Fishes - Behavior, Ecology and Evolution. Chapman and Hall, London, 60-85.

Mazzuchelli J, Martins C (2009) Genomic organization of repetitive DNAs in the cichlid fish Astronotus ocellatus. Genetica 136: 461-469. doi: 10.1007/s10709-008-9346-7

McCusker MR, Paterson IG, Bentzen P (2008) Microsatellite markers discriminate three species of North Atlantic wolffishes (Anarhichas spp.). Journal of Fish Biology 72: 375-385. doi: 10.1111/j.1095-8649.2007.01701.x

Nadir E, Margalit HT, Gallily T, Ben-Sasson SA (1996) Microsatellite spreading in the human genome: Evolutionary mechanisms and structural implications. Proceedings of the National Academy of Sciences of the USA 93: 6470-6475. doi: 10.1073/pnas.93.13.6470

Nakajima RT, Cabral-de-Mello DC, Valente GT, Venere PC, Martins C (2012) Evolutionary dynamics of rRNA gene clusters in cichlid fish. BMC Evolutionary Biology 12: 198. doi: $10.1186 / 1471-2148-12-198$ 
Padeken J, Zeller P, Gasser SM (2015) Repeat DNA in genome organization and stability. Current Opinion in Genetics \& Development 31: 12-19. doi: 10.1016/j.gde.2015.03.009

Palmieri N, Kosiol C, Schlötterer C (2014) The life cycle of Drosophila orphan genes. eLife 3: 1-21. doi: 10.7554/eLife.01311

Passos KB, Leão ASA, Oliveira DP, Farias IP, Hrbek T (2010) Polymorphic microsatellite markers for the overexploited Amazonian fish, Semaprochilodus insignis (Jardine and Schomburgk 1841). Conservation Genetics Resources 2: 231-234. doi: 10.1007/s12686$010-9245-y$

Pathak D, Ali S (2012) Repetitive DNA: A tool to explore animal genomes/ transcriptomes. In: Germana M, Petrera F (Eds) Functional genomics. InTech, Published, 155-180. doi: $10.5772 / 48259$

Perpelescu M, Fukagawa T (2011) The ABCs of CENPs. Chromosoma 120: 425-446. doi: $10.1007 /$ s00412-011-0330-0

Pinkel D, Straume T, Gray JW (1986) Cytogenetic analysis using quantitative, high-sensitivity, fluorescence hybridization. Proceedings of the National Academy of Sciences of the USA 83: 2934-2938. doi: 10.1073/pnas.83.9.2934

Plohl M, Mesltrovin N, Bruvo B, Ugarkovic D (2008) Similarity of structural features and evolution of satellite DNAs from Palorus subdepressus (Coleoptera) and related species. Journal of Molecular Evolution 46: 234-239. doi: 10.1007/PL00006298

Pokorná M, Kratochvíl L, Kejnovský E (2011) Microsatellite distribution on sex chromosomes at different stages of heteromorphism and heterochromatinization in two lizard species (Squamata: Eublepharidae: Coleonyx elegans and Lacertidae: Eremias velox). BMC Genetics 12: 90. doi: 10.1186/1471-2156-12-90

Poletto AB, Ferreira IA, Cabral-de-Mello DC, Nakajima RT, Mazzuchelli J, Ribeiro HB, Venere PC, Nirchio M, Kocher TD, Martins C (2010) Chromosome differentiation patterns during cichlid fish evolution. BMC Genetics 11: 50. doi: 10.1186/1471-2156-11-50

Racey PA, Barratt EM, Burland TM, Deaville R, Gotelli D, Jones G, Piertney SB (2007) Microsatellite DNA polymorphism confirms reproductive isolation and reveals differences in population genetic structure of cryptic pipistrelle bat species. Biological Journal of the Linnean Society 90: 539-550. doi: 10.1111/j.1095-8312.2007.00746.x

Santaguida S, Musacchio A (2009) The life and miracles of kinetochores. EMBO Journal 28: 2511-2531. doi: 10.1038/emboj.2009.173

Schliewen UK, Tautz D, Pääbo S (1994) Sympatric speciation suggested by monophyly of crater lake cichlids. Nature 368: 629-632. doi: 10.1038/368629a0

Schlötterer C (2000) Evolutionary dynamics of microsatellite DNA. Chromosoma 109: 365-371. doi: $10.1007 /$ s004120000089

Schlötterer C (2015) Genes from scratch - the evolutionary fate of de novo genes. Trends in Genetics 31: 215-219. doi: 10.1016/j.tig.2015.02.007

Schneider CH, Gross MC, Terencio ML, Artoni RF, Vicari MR, Martins C, Feldberg E (2013a) Chromosomal evolution of neotropical cichlids: the role of repetitive DNA sequences in the organization and structure of karyotype. Reviews in Fish Biology and Fisheries 23: 201-214. doi: 10.1007/s11160-012-9285-3 
Schneider CH, Gross MC, Terencio ML, Carmo EJ, Martins C, Feldberg E (2013b) Evolutionary dynamics of retrotransposable elements Rex1, Rex3 and Rex6 in Neotropical cichlids genome. BMC Evolutionary Biology 13: 152. doi: 10.1186/1471-2148-13-152

Seehausen O (2006) African cichlid fish: a model system in adaptive radiation research. Proceedings of the Royal Society B: Biological Sciences 273: 1987-1998. doi: 10.1098/ rspb.2006.3539

Smith WL, Chakrabarty P, Sparks JS (2008) Phylogeny, taxonomy, and evolution of Neotropical cichlids (Teleostei: Cichlidae: Cichlinae). Cladistics 24: 625-641. doi: 10.1111/j.10960031.2008.00210.x

Sonay TB, Carvalho T, Robinson MD, Greminger MP, Krützen M, Comas D, Highnam G, Mittelman D, Sharp A, Bonet TM, Wagner A (2015) Tandem repeat variation in human and great ape populations and its impact on gene expression divergence. bioRxiv. doi: 10.1101/015784

Tautz D, Renz M (1984) Simple sequences are ubiquitous repetitive components of eukaryotic genomes. Nucleic Acids Research 25: 4127-4138. doi: 10.1093/nar/12.10.4127

Teixeira WG, Ferreira IA, Cabral-de-Mello DC, Mazzuchelli J, Valente GT, Pinhal D, Poletto AB, Venere PC, Martins C (2009) Organization of repeated DNA elements in the genome of the cichlid fish Cichla kelberi and its contributions to the knowledge of fish genomes. Cytogenetic and Genome Research 125: 224-234. doi: 10.1159/000230006

Terencio ML, Schneider CH, Gross MC, Vicari MR, Farias IP, Passos KB, Feldberg E (2013) Evolutionary dynamics of repetitive DNA and sex chromosomes: Semaprochilodus (Characiformes, Prochilodontidae) as a model. Sexual Development 7: 325-333. doi: 10.1159/000356691

Torres GA, Gong Z, Iovene M, Hirsch CD, Buell CR, Bryan GJ, Novák P, Macas J, Jiang J (2011) Organization and evolution of subtelomeric satellite repeats in the potato genome. Genetics 1: 85-92. doi: 10.1534/g3.111.000125

Valente GT, Mazzuchelli J, Ferreira IA, Poletto AB, Fantinatti BEA, Martins C (2011) Cytogenetic mapping of the retroelements $\operatorname{Rex} 1, \operatorname{Rex} 3$ and $\operatorname{Rex} 6$ among cichlid fish: new insights on the chromosomal distribution of transposable elements. Cytogenetic and Genome Research 133: 34-42. doi: 10.1159/000322888

Verdaasdonk JS, Bloom K (2011) Centromeres: unique chromatin structures that drive chromosome segregation. Nature Reviews Molecular Cell Biology 12: 320-332. doi: 10.1038/nrm3107

Vicari MR, Artoni RF, Moreira-Filho O, Bertollo LAC (2006) Basic and molecular cytogenetics in freshwater Cichlidae (Osteichthyes, Perciformes). Karyotypic conservationism and divergence. Caryologia 59: 260-266. doi: 10.1080/00087114.2006.10797924

Vinces M, Legendre M, Caldara M, Hagihara M, Verstrepen K (2009) Unstable tandem repeats in promoters confer transcriptional evolve ability. Science 324: 1213-1216. doi: 10.1126/science. 1170097

Wren J, Forgacs E, Fondon J, Pertsemlidis A, Cheng S, Gallardo T, Williams R, Shohet R, Minna J, Garner H (2000) Repeat polymorphisms within gene regions: phenotypic and evolutionary implications. American Journal of Human Genetics 67: 345-356. doi: $10.1086 / 303013$ 